\title{
N-TERMINAL PRO-B-TYPE NATRIURETIC PEPTIDES IN INFANTS AND CHILDREN WITH NON-CARDIAC DISEASES
}

\author{
Humaira Ali, Junaid M Azam, Shazia Naureen \\ Liaquat National Hospital, Karachi Pakistan
}

\begin{abstract}
Objective: To evaluate the levels of N-terminal pro-B-type Natriuretic Peptide in infants and children with non-cardiac diseases especially respiratory diseases.

Study Design: Cross-sectional study.

Place and Duration of Study: Department of Chemical Pathology/Biochemistry Laboratory Services of Liaquat National Hospital Karachi Pakistan, from Dec 2018 to Nov 2019.

Methodology: Infants and children admitted to the Pediatric department with non-cardiac diseases were included in the study. Non-probability consecutive sampling was done. Blood was taken and analyzed for N- terminal pro-B-type Natriuretic Peptide, Troponin I, urea, creatinine, Lactate dehydrogenase, Creatinine Kinase, lactate and sodium analysis.

Results: Out of the 93 patients, $74(80 \%)$ were diagnosed with respiratory disorders, with bronchopneumonia making up 54 (59\%) Bronchiolitis $15(17 \%)$ and $4 \%$ had miscellaneous respiratory diseases. Out of the remaining $20 \%, 8(9 \%)$ patients were diagnosed with sepsis, and the remaining $11 \%$ were diagnosed with miscellaneous diseases. There was a positive correlation of N- terminal pro-B-type Natriuretic Peptide with Troponin I, urea, creatinine, Creatinine Kinase and Lactate dehydrogenase levels $(p<0.05)$.

Conclusion: N- terminal pro-B-type Natriuretic Peptide levels were found to be raised in pediatric patients with non-cardiac diseases especially broncho-pneumonia and in future it may be used as a marker of bronchopneumonia in children.
\end{abstract}

Keywords: N- terminal pro-b-type natriuretic peptide, Non-cardiac diseases, Pediatric patients.

\footnotetext{
This is an Open Access article distributed under the terms of the Creative Commons Attribution License (https://creativecommons.org/licenses/by-nc/4.0/), which permits unrestricted use, distribution, and reproduction in any medium, provided the original work is properly cited.
}

\section{INTRODUCTION}

B-type natriuretic peptide (BNP) and N-Terminal pro-BNP (NT pro-BNP) are natriuretic peptides (NPs) mainly released from the cardiac ventricles ${ }^{1,2}$. The main stimulus for secretion is myocardial wall stress, with pressure or volume overload ${ }^{1}$. Recently, pro-inflammatory cytokines and sympathetic activity have been identified as triggers for BNP/NT pro-BNP secretion ${ }^{1}$. This may explain elevated levels of BNP/NT proBNP in patients with normal ventricular function ${ }^{1}$. The biological effects of BNP include vasodilatation, natriure-sis, diuresis and down-regulation of the reninangio-tensin-aldosterone system ${ }^{1}$. NT-proBNP has an un-known function and is thought to be cleared mainly by the kidneys; therefore it is more sensitive to changes in renal function ${ }^{1,2}$.

BNP, NT pro-BNP and Atrial Natriuretic peptide (ANP) are used as cardiac markers for the diagnosis of cardiac failure and to differentiate dyspnoea due to cardiac failure or due to pulmonary or non-cardiac disease $^{1-3}$. This has also been studied in pediatric patients and it has been seen that children with severe heart failure had the highest mean plasma NT pro-BNP,

Correspondence: Dr Humaira Ali, B-3, Al-Habib Gardens, Block 9, Clifton Colony, Karachi Pakistan

Received: 27 Jan 2020; revised received: 03 Jun 2020; accepted: 15 Jun 2020 compared to the patients with moderate or mild heart failure $^{4}$. A new role of the natriuretic peptides (NPs) have been found in pulmonary medicine especially pneumonia in which NP levels are seen to be elevated in the grey zone between normal and highly elevated values seen in cardiac failure ${ }^{1}$.

In well defined groups of patients with pulmonary disease, the NPs may provide useful diagnostic and prognostic information. NP levels are increased in stable and acute cases of Chronic Obstructive Pulmonary Disease (COPD) and Community Acquired Pneumonia (CAP) in adults ${ }^{5-7}$. NPs are used as markers of cardiac failure in infants and children, in the screening, diagnosis, management and follow-up of children with heart failure due to a number of diseases ${ }^{8}$. These peptide levels have been found to be increased in children with non-cardiac diseases and acute infections also. So the role of these peptides should be known in pediatric non-cardiac diseases so that elevated NP levels are not misinter-preted as cardiac disease ${ }^{9}$. The levels of NT pro-BNP have been shown to be highest in the first days of life, decline rapidly in the first few weeks and then gradually decline with age ${ }^{10}$. Very little work has been done on NP levels in pediatric non-cardiac diseases mainly pulmonary diseases and this was the aim of our study to evaluate the role of NPs in non-cardiac diseases in infants and children. 


\section{METHODOLOGY}

This was a cross-sectional study performed in the department of Chemical Pathology/Biochemistry Laboratory Services of Liaquat National Hospital Karachi, from December 2018 to November 2019 after approval by the ethical review committee in a certificate dated 26/12/2019.

Infants and children are admitted to the Pediatric department with respiratory diseases e.g. Bronchopneumonia, chronic obstructive pulmonary diseases (COPD), health care associated pneumonia (HCAP), aspiration pneumonia (AP), community acquired pneumonia (CAP) etc were included in the study after taking informed consent. Non-probability consecutive sampling was done. Infants and children of either gender, from birth till 12 years of age, having been diagnosed with non-cardiac respiratory diseases, for example pneumonia and COPD were included in the study. Children with known heart disease, or with signs and symptoms of heart disease were not included. By taking mean $B N P$ value $=459.55 \pm 422.61^{11}$, level of significance $(\alpha)=5 \%$, power of test $(1-\beta)=80 \%$, test value of mean $=300$, the calculated sample size was 73 patients with the help of WHO software for sample size calculation taking 95\% confidence level. The blood sample was taken for the analysis of NT pro-BNP. Four $\mathrm{ml}$ of venous blood was collected in a green top tube containing lithium heparin which is an anticoagulant. The samples were centrifuged and the supernatant was collected for the analysis. To perform NT pro-BNP and Troponin I (Trop-I) the plasma was analyzed by Electrochemiluminescence Immunoassay using Elecsys e411 (Roche Diagnostics) and the cutoffs used were 01 month-1 year $<650 \mathrm{pg} / \mathrm{ml}, 1-2$ years $<400 \mathrm{pg} / \mathrm{ml}, 2-6$ years $<300 \mathrm{pg} / \mathrm{ml}, 6-18$ years $<160$ $\mathrm{pg} / \mathrm{ml}$ for NT pro-BNP ${ }^{12}$. For urea, creatinine, lactate dehydrogenase (LDH), creatinine kinase (CK), Lactate analysis, spectrophotometry was used in c501 (roche diagnostics). For sodium estimation, Ion selective electrode (ISE) using NOVA was the method of choice. The cutoffs for Trop I, urea, creatinine were $>0.3 \mathrm{ng} / \mathrm{ml}$, $>50 \mathrm{mg} / \mathrm{dl}$ and $>1.5 \mathrm{mg} / \mathrm{dl}$ respectively. For CK the reference interval used was 0-3 years 60-305 U/L, 4-6 years $75-230 \mathrm{U} / \mathrm{L}, 7-9$ years $60-365 \mathrm{U} / \mathrm{L}^{13}$. For lactate, $>26 \mathrm{mg} / \mathrm{dl}$ in neonates and $>19.8$ in pediatric patients were used. For LDH in children 2-15 years $120-300$ $\mathrm{U} / \mathrm{L}$ and sodium $0-11$ months $133-142 \mathrm{mEq} / \mathrm{L}$ and $\geq 1$ year $136-145 \mathrm{mEq} / \mathrm{L}$ were used respectively. All samples were screened and the final diagnosis was made. Confounding variables as well as biasness were controlled by strictly following the inclusion and exclusion criteria. All the data including patient demographics and laboratory findings were recorded. Data was analyzed using Statistical Package for Social Sciences version-21. Mean and SD were calculated for the quantitative variables i.e. age, NT pro-BNP, Trop I, urea and creatinine. Frequency and percentages were calculated for qualitative variables i.e. gender.

\section{RESULTS}

A total of 93 samples were obtained with a minimum age of 1 month and a maximum age of 132 months. Mean age was 13.1 months with an SD of 23.4. The gender frequency and percentage are given in table-I.

Out of the 93 patients, 74 (80\%) were diagnosed with respiratory disorders, with Bronchopneumonia making up $54(59 \%)$, bronchiolitis $15(17 \%)$, aspiration pneumonia $2(2 \%)$, acute exacerbation of asthma $1(1 \%)$ and reactive airway disease $1(1 \%)$. Out of the remaining 20\%, $8(9 \%)$ patients were diagnosed with Sepsis, $2(2 \%)$ had meningitis/meningoencephalitis, 2 (2\%) had acute gastroenteritis, 2 (2\%) had Cystic Fibrosis with complications. There was 1 case each (Total 5\%) of Hypernatremic dehydration with fits, Developmental delay with seizure disorders, abdominopereneal pull-through, acute glomerulonephritis and measles with complications.

Table-I: Gender frequency and percentage.

\begin{tabular}{c|c|c}
\hline Gender & Frequency & Percentage \\
\hline Male & 57 & 61.3 \\
\hline Female & 36 & 38.7 \\
\hline Total & 93 & 100 \\
\hline
\end{tabular}

Table-II: Frequencies of normal and abnormal levels of the different parameters.

\begin{tabular}{l|c|c|c}
\hline Parameters & $\begin{array}{c}\text { Normal } \\
\text { Values }\end{array}$ & $\begin{array}{c}\text { Elevated } \\
\text { Values }\end{array}$ & $\begin{array}{c}\text { Decreased } \\
\text { Values }\end{array}$ \\
\hline NT pro-BNP & $74(80 \%)$ & $19(20 \%)$ & NA \\
\hline Troponin I & $87(94 \%)$ & $6(6 \%)$ & NA \\
\hline Urea & $80(86 \%)$ & $13(14 \%)$ & NA \\
\hline Creatinine & $90(97 \%)$ & $3(3 \%)$ & NA \\
\hline $\begin{array}{l}\text { Creatinine } \\
\text { kinase }\end{array}$ & $72(77 \%)$ & $21(23 \%)$ & NA \\
\hline $\begin{array}{l}\text { Lactate } \\
\text { Dehydrogenase }\end{array}$ & $25(27 \%)$ & $68(73 \%)$ & NA \\
\hline Lactate & $27(29 \%)$ & $66(71 \%)$ & NA \\
\hline Sodium & $73(79 \%)$ & $18(19 \%)$ & $2(2 \%)$ \\
\hline NA: Not Applicable & &
\end{tabular}

As regards the blood workup, 19 (20\%) had NT pro-BNP which was normal for the age and $74(80 \%)$ had elevated NT pro-BNP levels (table-II). In the 
collected samples, Trop I, Urea, creatinine, CK, LDH, Lactate and sodium were also tested. The frequencies of the values within the reference interval, elevated and decreased are shown in table-II.

Table-III: As regards the correlation of NT pro-BNP with the different parameters, there was a positive correlation of NT pro-BNP with Trop I, urea, creatinine, CK and LDH levels $(p<0.05)$. Correlation of $\mathbf{N}$ Terminal Pro BNP with the different parameters NT pro BNP.

\begin{tabular}{l|c|c}
\hline & Pearson Correlation & $p$-value \\
\hline Age (In Months) & -0.065 & 0.581 \\
\hline Troponin I & 0.356 & $<0.001$ \\
\hline Urea & 0.515 & $<0.001$ \\
\hline Creatinine & 0.523 & $<0.001$ \\
\hline Lactic Acid & 0.058 & 0.581 \\
\hline Creatinine Kinase & 0.264 & 0.011 \\
\hline Lactate Dehydrogenase & 0.254 & 0.014 \\
\hline Sodium & -0.006 & 0.951 \\
\hline
\end{tabular}

\section{DISCUSSION}

Very little research has been done with NT proBNP in pediatric respiratory diseases. However it has been well studied in adults. In a study conducted in Japan, they compared BNP levels of patients diagnosed as community acquired pneumonia (CAP) with aspiration pneumonia (AP), health care associated pneumonia (HCAP) and pneumonia with acute heart failure (PAHF) ${ }^{14}$. They found elevated BNP levels in all these conditions with very high levels in pneumonia associated with heart failure ${ }^{14}$. They also found that a high BNP level at admission was a predictor of CAP related death and BNP level was accurate in predicting mortality due to CAP also $^{14}$. Usuda et $a^{14}$, have used cut offs of $100 \mathrm{pg} / \mathrm{ml}, 200 \mathrm{pg} / \mathrm{ml}$ and $300 \mathrm{pg} / \mathrm{ml}$ and have devised an optimal cut off of $224.1 \mathrm{pg} / \mathrm{ml}$ for predicting death ${ }^{14}$. In adults we can use single cut offs but in pediatric patients, NT pro-BNP levels are high even in normal children so a single cut off cannot be used.

Nir et al12, published a review article in which they have used combined data from four different studies and calculated the $95^{\text {th }}$ percentile for NT proBNP levels and the cutoffs for the different pediatric age groups and given the cutoffs of $>12,000 \mathrm{pg} / \mathrm{ml}$ in the first 2 days of life, days 3-11 $(>6,000 \mathrm{pg} / \mathrm{ml}), 1$ month to 1 year $(>650 \mathrm{pg} / \mathrm{ml}), 1-2$ years $(>400 \mathrm{pg} / \mathrm{ml})$, $2-6$ years $\left(>300 \mathrm{pg} / \mathrm{ml}\right.$ and $6-18$ years $\left(>160 \mathrm{pg} / \mathrm{ml}^{12}\right.$. These are the cutoffs used by us in our study.

NT pro-BNP has been studied in pediatric cardiac diseases and elevated values have been found in patients with congenital heart diseases, cardiomyo- pathies, heart failure and pulmonary artery hypertension and high NT pro-BNP levels were associated with high morbidity and mortality ${ }^{15,16}$.

Regarding NT pro-BNP in pediatric lung diseases, a study by Orwoll et al17, has shown that NT pro-BNP levels are raised in pediatric patients with acute respiratory distress syndrome and acute lung Injury ${ }^{17}$. Noori et al ${ }^{18}$, studied NT pro-BNP levels in neonates with cardiac and respiratory diseases as well as healthy controls and found that cardiac patients had the highest level of NT pro-BNP, followed by respiratory patients with healthy controls having the lowest level of the analyte ${ }^{18}$. We have also found high NT pro-BNP levels in pediatric patients with respiratory diseases even while using the high levels of cutoffs as suggested by Nir et all2. Lange et al19, studied children with pneumonia and concluded that NT pro-BNP has shown promise in the stratification of the severity of childhood pneumonia ${ }^{19}$. Osarogiagbon et al ${ }^{11}$, studied NT pro-BNP levels in children with pneumonia and found higher values as compared to the levels in healthy children ${ }^{11}$. The children who died had higher values as compared to those who were discharged, showing the prognostic value of NT pro-BNP11. This is similar to our study although we have not studied the outcome of these patients.

A study by Wu et al ${ }^{20}$, found elevated BNP levels in patients with sepsis and septic shock and they also found increased levels in severe shock along with cardiac dysfunction and mortality and they claim that BNP could be used as a tool for risk stratification ${ }^{20}$. In our study also, NT pro-BNP levels were found to be raised in patients with sepsis. Nevo $\mathrm{et}^{\mathrm{al}}{ }^{9}$, measured NT pro-BNP in children with acute non-cardiac diseases and they found elevated levels in children with gastroenteritis, dehydration, respiratory tract infection, fever due to bacterial and viral disease etc ${ }^{9}$. This is similar to our study which shows elevated levels in respiratory tract infection and inflammation, sepsis, gastroenteritis and meningitis/meningoencephalitis. Mittelstaedt et al21, studied children with systemic inflammatory response syndrome (SIRS) and found highly elevated NT pro-BNP levels was associated with increased morbidity in these patients.

Nevo et al ${ }^{9}$, correlated NT pro-BNP with many parameters. They found a positive correlation with creatinine and a negative correlation with weight ${ }^{9}$. No correlation was found with Liver Function Tests (LFTs), sodium, potassium, glucose or Lactate Dehydrogenase $(\mathrm{LDH})^{9}$. These findings are similar to our 
study which shows a positive correlation of NT proBNP with Trop I, urea, creatinine, CK and LDH levels $(p<0.05)$. There was no correlation of NT pro-BNP with lactate. The reason of the positive correlation with urea and creatinine levels could be that NT pro-BNP is excreted via the kidneys and in case of renal impairment, NT pro-BNP levels will rise in the body.

The limitation of this study was the small sample size and different reference intervals of the age groups due to which a small number of patients were present in each age group. Large multicenter studies are recommended for this purpose.

\section{CONCLUSION}

NT pro-BNP levels were found to be raised in pediatric patients with non-cardiac diseases especially bronchopneumonia and in future it may be used as a prognostic marker of bronchopneumonia in children.

\section{CONFLICT OF INTEREST}

This study has no conflict of interest to be declared by any author.

\section{REFERENCES}

1. Salerno D, Marik PE. Brain natriuretic peptide measurement in pulmonary medicine. Respir Med 2011; 105(12): 1770-75.

2. Burtis C, Bruns D. Teitz Fundamentals of Clinical Chemistry and Molecular Diagnostics. 2015; 7th edition Avalibal at Internet. https://www.elsevier.com/books/tietz-fundamentals-ofclinical-chemistry-and-molecular-diagnostics/burtis/978-1-45574165-6.

3. Gangnus T, Burckhardt BB. Potential and limitations of atrial natriuretic peptide as biomarker in pediatric heart failure - a comparative review. Frontiers Pediatr 2019; 6(1): 420(1): 1-14.

4. Isah IA, Sadoh WE, Iduoriyekemwen NJ. Usefulness of amino terminal pro-B-type natriuretic peptide in evaluating children with cardiac failure. Cardiovasc Diagn Ther 2017; 7(4): 380-88.

5. Hawkins NM, Khosla A, Virani SA, McMurray JJV, FitzGerald JM. B-type natriuretic peptides in chronic obstructive pulmonary disease: a systematic review. BMC Pulmon Med 2017; 17(11): $1-17$.

6. Adrish M, Nannaka VB, Cano EJ, Bajantri B, Diaz-Fuentes G. Significance of NT-pro-BNP in acute exacerbation of COPD patients without underlying left ventricular dysfunction. Inter J COPD 2017; 2017(12): 1183-89.

7. Hausman-Kedem M, Reif S, Danino D, Limor R, Grinspan ZM, Yerushalmi-Feler A, et al. Mechanism of hyponatremia in com- munity-acquired pneumonia. does b-type natriuretic peptide play a causative role? Pediatric Emergency Care 2018; 34(9): 64146.

8. Cantinotti M, Law Y, Vittorini S, Crocetti M, Marco M, Murzi B, et al. The potential and limitations of plasma BNP measurement in the diagnosis, prognosis, and managment of children with heart failure due to congenital cardiac disease: an update Heart Fail Rev 2014; 19(1): 727-42.

9. Nevo I, Erlichman M, Algur N, Nir A. N-terminal pro B-type natriuretic peptide levels in infants and children with acute noncardiac diseases. Isr Med Assoc J 2011; 13(7): 420-24.

10. Vijlbrief DC, Benders MJNL, Kemperman H, Bel Fv, de Vries WB. Use of cardiac biomarkers in neonatology. Pediatr Res 2012; 72(7): 337-43.

11. Osarogiagbon WO, Sadoh WE. Socio-economic and Socio-demographic Determinants of BNP values in children with Pneumonia In Benin City. Acad Manag J 2017; 10(5): 432-38.

12. Nir A, Lindinger A, Rauh M, Bar-Oz B, Laer S, Schwachtgen L, et al. NT-pro-B-type natriuretic peptide in infants and children: reference values based on combined data from four studies. Pediatr Cardiol 2009; 30(1): 3-8.

13. Andropoulos DB. Pediatric normal laboratory values. gregory's pediatric anesthesia 2012; Fifth Edition: appendix B [Internet] Available at: https://onlinelibrary.wiley.com/doi/abs/10.1002/ 9781444345186.app2.

14. Usuda D, Sangen R, Hashimoto Y, Muranaka E, linuma Y, Kanda T. Validation of a B-type natriuretic peptide as a prognostic marker in pneumonia patients: a prospective cohort study. BMJ Open 2016; 6(1): 1-10.

15. Oishi PE, Ridley F, Datar SA, Fineman JR. B-Type natriuretic peptide (bnp) in neonates, infants and children undergoing cardiac surgery. Front Lines Thoracic Surg 2012; 1(1): 978-953-307915-8.

16. Singhal N, Saha A. Bedside biomarkers in pediatric cardio renal injuries in emergency. Int J Crit Illn Inj Sci 2014; 4(3): 238-46.

17. Orwoll BE, Sapru A. Biomarkers in pediatric ards: future directions. Front Pediatr 2016; 4(6): 1-15.

18. Noori NM, Savadkoohi S, Teimouri A, Alizadeh F. Evaluation of serum levels of n-terminal pro brain natriuretic peptide and atrial natriuretic peptide in neonates with respiratory distress. Int J Pediatr 2016; 4(30): 1847-56.

19. Lange J, Marczak H, Krenke K, Peradzyńska J. NT pro-NB as a marker of the pneumonia severity in children. Eur respirat J 2019; 54(Supp163): PA994-10.

20. Wu JR, Chen IC, Dai ZK, Hung JF, Hsu JH. Early elevated b-type natriuretic peptide levels are associated with cardiac dysfunction and poor clinical outcome in pediatric septic patients. Acta Cardiol Sin 2015; 31(6): 485-93.

21. Mittelstaedt EV, Kobayashi D. Impact of NT-proBNP on Clinical Outcomes in Children with Systemic Inflammatory Response Syndrome. Pediatr 2019; 144(2): 320-23. 